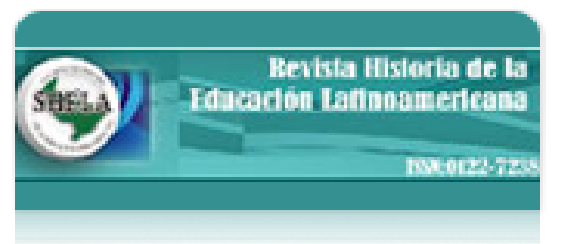

\title{
Revista Historia de la Educación Latinoamericana
}

\section{ISSN: 0122-7238}

rhela@uptc.edu.co

Universidad Pedagógica y Tecnológica de

Colombia

Colombia

\section{Vega y Ortega, Rodrigo}

La zoología y el Diario de los niños (ciudad de México, 1839-1840)

Revista Historia de la Educación Latinoamericana, vol. 15, núm. 20, enero-junio, 2013, pp. 275-293

Universidad Pedagógica y Tecnológica de Colombia

Boyacá, Colombia

Disponible en: http://www.redalyc.org/articulo.oa?id=86929738013

Cómo citar el artículo

- Número completo

- Más información del artículo

Página de la revista en redalyc.org

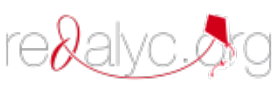

Sistema de Información Científica

Red de Revistas Científicas de América Latina, el Caribe, España y Portugal Proyecto académico sin fines de lucro, desarrollado bajo la iniciativa de acceso abierto 


\title{
La zoología y el Diario de los niños (ciudad de México, 1839-1840) ${ }^{1}$
}

\author{
Rodrigo Vega y Ortega ${ }^{2}$ \\ Colegio de Historia -UNAM - (México) \\ rodrigo.vegayortega@hotmail.com
}

Recepción: 27/03/2012

Evaluación: 01/04/2012

Aceptación: 06/06/2012

Artículo de Reflexión

DOI: http://dx.doi.org/ 10.9757/Rhela.20.12

\section{RESUMEN}

A mediados del siglo XIX en la ciudad de México se desarrollaron varios proyectos de divulgación científica en las revistas dirigidas a las clases media y alta. Uno de ellos fue el Diario de los Niños, primera publicación periódica mexicana infantil, que circuló entre 1839 y 1840. En esta revista se dieron a conocer varios artículos de Zoología desde las perspectivas instructiva, exótica y curiosa para instruir de forma amena a los infantes. El objetivo de la investigación es analizar los escritos, sobre la fauna, que estuvieron dirigidos al público infantil desde una narrativa amena y un lenguaje sencillo. El estudio de la divulgación zoológica es de gran relevancia para comprender las vías en que los menores de edad de México aprendían conocimientos científicos fuera del aula en una época en que las escuelas de primeras letras carecían de asignaturas de ciencia. Dicha Revista puso las bases para ampliar la cultura científica capitalina que se desarrolló con vigor en la segunda mitad de la centuria en distintos niveles de instrucción y en la educación informal. Es probable que algunos de los científicos mexicanos descubrieran su vocación científica en los escritos de esta Revista.

Palabras clave: Revista Historia de la Educación Latinoamericana, zoología, prensa, infancia, divulgación científica.

1 Esta investigación es parte del proyecto PAPIIT (IN 301113) "La Geografía y las ciencias naturales en algunas ciudades y regiones mexicanas, 1787-1940". Responsable Dra. Luz Fernanda Azuela, UNAM.

2 Maestro en Historia, profesor del Colegio de Historia de la Facultad de Filosofía y Letras-UNAM. Su línea de investigación es la Historia de la ciencia mexicana en el siglo XIX. Entre sus publicaciones se encuentran: "Difundir la instrucción de una manera agradable: Historia Natural y Geografía en revistas femeninas de México, 1840-1855", Revista Mexicana de Investigación Educativa Vol.: 16 No. 48 (2011): 107-129; "La Historia Natural en las revistas de artesanos de México, 1840-1855", Revista Complutense de Historia de América Vol.: 38 (2012): 153-175 y "Recreación e instrucción botánicas en las revistas de la ciudad de México, 1835-1855”, Historia Crítica No. 49 (2013): 109-133. 
The zoology and The newspaper of the children

(Mexico city, 1839-1840)

\author{
A zoologia e o Diario de los niños (cidade do \\ México, 1839-1840)
}

\section{RESUMO}

Em meados do século XIX, na cidade do México, se desenvolveram vários projetos de divulgação científica nas revistas dirigidas às classes média e alta. Um destes projetos foi o Diario de los Niños, primeira publicação periódica mexicana infantil, que circulou entre 1839 e 1840. Nesta revista se tornaram conhecidos vários artigos de Zoologia, a partir das perspectivas instrutiva, exótica e curiosa, para instruir de forma amena aos infantes. O objetivo da pesquisa é analisar os escritos sobre a fauna que estiveram dirigidos ao público infantil desde uma narrativa amena e uma linguagem sensível. O estudo da divulgação zoológica é de grande relevância para compreender os modos pelos quais os menores de idade do México aprendiam conhecimentos científicos fora da aula em uma época em que as escolas de primeiras letras não contavam com disciplinas de ciência. A referida revista colocou as bases para ampliar a cultura científica capitalina que se desenvolveu com vigor na segunda metade da centúria nos distintos níveis de instrução e na educação informal. É provável que alguns dos cientistas mexicanos tenham descoberto sua vocação científica nos textos desta revista.

Palavras-chave: Revista História da Educação Latino-americana, zoología, prensa infância, divulgação científica.
Key words: History of Latin American Education Journal, zoology, press, infancy, scientific publication.

\section{INTRODUCCIÓN}

En México, durante la última década, se han desarrollado varios estudios sobre la infancia en el siglo XIX que enfatizan el papel de la escuela de primeras letras en la construcción del futuro ciudadano. Las investigaciones históricas se han centrado en la segunda infancia, entendida en la época como la etapa de la vida que abarcaba de los 7 a 15 años. Esta se consideraba propicia para adquirir conocimientos elementales de lectura y escritura, 
destrezas aritméticas y nociones de moral. ${ }^{3}$ Se consideraba que eran los años en que los infantes estaban listos para incursionar en los saberes humanísticos y científicos en los ámbitos escolarizado ${ }^{4}$ e informal. ${ }^{5}$

La historia de la infancia mexicana ha mantenido un estrecho vínculo con la historia de la educación formal y ha dejado de lado las vías en que los niños y niñas, de estratos medio y alto, de ámbitos urbanos, aprendían saberes de todo tipo mediante estrategias informales, entre ellas, el impreso. Este escenario fue simultáneo a gran parte de los países de Europa y América. En efecto, "los historiadores se han preocupado por los cambios realizados por el Estado para mejorar la educación, ver las transformaciones y los nuevos proyectos educativos, y cómo estos afectaban a la sociedad", mediante las escuelas públicas y privadas. ${ }^{6}$ Sin embargo, a la par que algunos menores acudían a estas, en el hogar se fomentó el aprendizaje informal de las ciencias, entre otras disciplinas, mediante libros, folletos y revistas.

La historiografía tradicional ha hecho hincapié en que "la escuela se erigió en la institución de socialización y de inculcación de saberes, por lo que se convirtió en el lugar más transcendente para la enseñanza y el aprendizaje, sitio en que la razón debía cultivarse y moldearse". ${ }^{7}$ Bajo esta perspectiva, que supone al medio escolarizado como la vía primordial para adquirir conocimientos científicos bajo la anuencia del Estado, se ha dejado de lado que la instrucción informal se fomentó en el ámbito privado. Este tema aún no ha sido abordado de manera amplia por los historiadores mexicanos.

3 Pierre Caspard, "La infancia, la adolescencia, la juventud: para una economía política de las edades desde la época moderna", en La infancia y la cultura escrita, coord. Lucía Martínez (México: Siglo XXI/Universidad Autónoma de Morelos, 2001), 90.

4 La educación formal se refiere a aquella que para "su funcionamiento requiere de estructuras jerárquicas que sistematizan en grados cronológicamente determinados, un currículo desplegado en planes y programas prescritos para la educación por niveles", en este caso las primeras letras, y requiere que "los estudiantes estén matriculados y se sometan a evaluaciones formales, desde las cuales se acrediten los aprendizajes". Manuel Saavedra, Diccionario de Pedagogía. 500 términos especializados (México: Pax, 2001), 59.

5 La educación informal "consiste en cualquier experiencia educativa organizada fuera del sistema formal establecido, con el propósito de servir a una determinada población meta [...] Sus características son su intencionalidad y sistematicidad, aunque sin relación con el sistema regular formal y no conduce al otorgamiento de títulos convalidados por el sistema formal", aunque la divulgación del conocimiento es uno de sus pilares. Sergio Sánchez Cerezo, Diccionario de las ciencias de la educación (México: Santillana, 1997), 374.

6 Zoila Santiago, "Los niños en la historia. Los enfoques historiográficos de la infancia", Takwá No. 11-12 (2007): 32.

7 Antonio Padilla, "Rostros en el cristal: infancias y modalidades educativas (a modo de introducción)", en Arquetipos, memorias y narrativas en el espejo: infancia anormal y educación especial en los siglos XIX y XX, coord. Antonio Padilla (México: Juan Pablos editor, Universidad Autónoma del Estado de Morelos, 2012), 26. 
La situación educativa de los infantes fue compartida con otros grupos sociales urbanos que durante la primera mitad del siglo XIX adquirían conocimiento científico de tipo informal, ${ }^{8}$ como mujeres, agricultores y artesanos, gracias a la lectura de un conjunto heterogéneo de impresos periódicos. Los redactores de ellos (casi siempre varones adultos residentes de ciudades de cierto nivel social y parte de un selecto grupo de egresados de instituciones de instrucción secundaria) consideraron que la prensa era una vía amena, barata, amplia y asequible a los grupos medio y alto para instruir científicamente bajo la divulgación. ${ }^{9}$

Los proyectos de popularización científica fueron de carácter privado y paralelos a los esfuerzos estatales por escolarizar a la mayor cantidad de menores de edad del país. Los escritos divulgativos tenían por premisa propagar "una ciencia comprendida por todos" aplicada a la vida diaria del lector. ${ }^{10}$ Un grupo de hombres se ostentó como el generador y propagador de la ciencia, mientras que los infantes eran vistos como grupos alejados de esta, pero ávidos receptores de diversas disciplinas, como la Historia Natural.

La divulgación naturalista, entre los infantes, en la prensa inició con el Diario de los Niños. Literatura, Entretenimiento e Instrucción. Esta revista fue editada por Wenceslao Sánchez de la Barquera (1779-1840), quien consideró importante llevar la ciencia a los lectorcitos mediante la instrucción recreativa. Para ello, la revista se dividió en varias secciones, por ejemplo, "Botánica”, "Higiene", "Viajes", “Historia Natural”, “Curiosidades Científicas”, “Geografía”, "Meteorología” y “Maravillas de la Naturaleza”. Cabe señalar que en el terreno naturalista, la Zoología fue el tema con mayor cantidad de escritos.

Entre 1839 y 1840 se publicaron 3 volúmenes del Diario de los Niños. Los dos primeros se confeccionaron en la Imprenta de Miguel González y el último de ellos salió de la Imprenta de Vicente García Torres. Las medidas de cada

8 La educación científica, formal e informal, se desarrolla "a partir del planteamiento de problemas y construcción de hipótesis por verificar, tal que permita el descubrimiento de leyes y no su aprendizaje como algo acabado. Propicia el desarrollo de un espíritu creativo e innovador, el impulso de la intuición e imaginación, la facultad de observar, coleccionar, medir y clasificar los hechos, la elaboración de conclusiones y de la duda metódica que caracterizan a la investigación” de alguna ciencia. Manuel Saavedra, Diccionario de Pedagogía. 500 términos especializados (México: Pax, 2001), 57.

9 El término divulgación se refiere a poner al alcance de un público amplio los resultados de una actividad especializada, como la Zoología. El conocimiento a divulgar se transmite mediante diversas estrategias y medios de comunicación, por ejemplo la prensa destinada a un grupo social particular, en este caso los niños.

10 Moema de Rezende, "Ensaio sobre o termo 'vulgarização científica' no Brasil do século XIX”, Revista Brasileira de História da Ciência Vol: 1 No 2 ( 2008): 139. 
volumen son de $25 \times 16 \mathrm{~cm}$. Cada fascículo consta de un promedio de 24 páginas que conformaron cada volumen de aproximadamente 400 páginas. El costo era de 2 reales en la ciudad de México y 3 reales en el interior. ${ }^{11}$

El Diario de los Niños fue parte de una empresa cultural compartida por varios impresores europeos y americanos que creyeron fundamental la modernización de la instrucción infantil en el hogar. Tal empresa se remonta a Inglaterra en el siglo XVIII cuando se publicaron The Lilliputian Magazine (1751) y The Juvenille Magazine (1788); mientras que en Francia fue popular el Journal d'Education (1768); en España se editó la Gaceta de los Niños (1798); y en Estados Unidos circuló The Youth's Newspaper (1797). El redactor retomó las experiencias de dichas revistas para ofrecer una interesante publicación mexicana a los lectorcitos del país.

En las secciones temáticas señaladas se publicaron contenidos zoológicos que permiten adentrarse en el estudio de la instrucción informal de las ciencias en los hogares de niños de estratos medio y alto de la ciudad de México que, posiblemente, años después se interesaron en el estudio de la naturaleza como profesión, gracias al Diario de los Niños. Cabe suponer que algunos escritos naturalistas despertaron la vocación de varios de los futuros ingenieros, médicos, farmacéuticos, botánicos y zoólogos de la segunda mitad del siglo XIX mexicano.

El objetivo de esta investigación es analizar una muestra representativa de los once escritos de divulgación zoológica de corte infantil que se dieron a conocer en el Diario de los Niños. Así, se pretende ensanchar los estudios de historia social de la ciencia en cuanto a la popularización de la Zoología a través de la prensa infantil, que posiblemente interesaron a diversos lectores. Esto permitirá comprender el acercamiento de las ciencias naturales por parte del público, a la par que estudiar el interés de los padres de familia que compraban la revista para que sus hijos e hijas se adentraran en la cultura científica más allá de la escuela.

La metodología de la investigación se basa en la historia social de la ciencia que en las últimas décadas se ha desarrollado de forma amplia en Estados

11 Miguel Ángel Castro y Guadalupe Curiel, Publicaciones periódicas mexicanas del siglo XIX: 1822-1855 (México: Universidad Nacional Autónoma de México, 2000), 130-131. 
Unidos, Inglaterra, España, Alemania y Francia. ${ }^{12}$ Sin embargo, en México todavía son insuficientes los estudios en este tenor, ya que la historiografía de la ciencia mexicana se ha concentrado en la relación ciencia-estado, ciencia-política y ciencia-nación. Este tema es de interés para la historia social de la ciencia al plantear que las disciplinas científicas forman parte de la cultura, pues el conocimiento creado por ellas se divulgaba mediante la prensa dirigida a distintos grupos de individuos, en este caso los infantes. Este enfoque historiográfico revela cómo el conocimiento científico afecta a diversos grupos sociales en un contexto determinado. ${ }^{13}$

\section{El público infantil hacia $1839-1840$}

Los niños que posiblemente leyeron el Diario de los Niños se encontraban en la segunda infancia, vivían en un entorno urbano y formaban parte de estratos medio y alto, en los cuales la lectura era indispensable para distanciarse del 'populacho'. Es de presumir que los lectorcitos asistían a alguna de las escuelas de la ciudad de México, ya fueran públicas o privadas para varones, parroquiales y de parcialidades de indios que sumaban 3611 alumnos para 1840, muchas de las cuales estaban basadas en los preceptos educativos de Joseph Lancaster (1778-1838). ${ }^{14}$ En el caso de las niñas, las escuelas particulares eran conocidas como 'Amigas', pero también hubo escuelas públicas, parroquiales, conventuales y de obras pías que acogían a 3280 alumnas en la misma época. ${ }^{15}$ También hay que tomar en cuenta a los niños y niñas que recibían educación de preceptores particulares en el hogar.

En las asignaturas de las escuelas de primeras letras se enseñaba a leer, escribir, Aritmética y Doctrina Cristiana y Civil, por lo cual los conocimientos científicos se aprendían fuera del aula, a través de los impresos, preceptores particulares y el entorno familiar. Mientras el aprendizaje en las escuelas se centraba en la memorización de los conocimientos elementales, las revistas privilegiaban una instrucción amena basada en el disfrute de los escritos sin necesidad de presentar evaluaciones ante un docente. Esta cuestión podía "favorecer la reflexión sobre su objeto e incluso su cuestionamiento",

\footnotetext{
12 Véase Jonathan Topham, "Scientific Publishing and the Reading of Science in Nineteenth-century Britain: A Historiographical Survey and Guide to Sources", Studies in History and Philosophy of Science No. 31 (2000): 559-612.

13 Peter Burke, Historia social del conocimiento. De Gutemberg a Diderot (Barcelona: Paidós, 2002): 233.

14 Véase Dorothy Tanck, La educación ilustrada 1786-1836. Educación primaria en la ciudad de México (México: El Colegio de México, 2005).

15 Tanck, La educación ilustrada, 197.
} 
pues los contenidos estaban narrados con base en experiencias cercanas a la vida infantil. ${ }^{16}$

Una vez que los niños aprendían a leer entraban en contacto con libros para ejercitarse y aprender distintos conocimientos, algunos cercanos a las ciencias naturales, por ejemplo las Fábulas (1781) de Félix María de Samaniego, las Fábulas literarias (1782) de Tomás de Iriarte y las Fábulas morales para la provechosa recreación de los niños que cursan las escuelas de primeras letras (1802) del Br. José Ignacio Basurto. En estos libros los niños tenían a su alcance "una historia sencilla, fácil de comprender por los destinatarios", que en ocasiones estaba articulada mediante personajes del reino animal. ${ }^{17}$ Esto estuvo a tono con la recomendación de Lancaster de emplear libros religiosos y de Historia Natural para el aprendizaje de la lectura en las escuelas que seguían sus preceptos. ${ }^{18}$

Las fábulas empleaban la fauna del mundo para trasmitir conocimientos de todo tipo, acorde con la edad de los lectores. El público se instruía mediante una "lectura agradable y divertida, además de permitir el acceso a una cultura literaria" que aproximaba las ciencias naturales a los niños. ${ }^{19} \mathrm{En}$ el siglo XIX, la literatura infantil continuó aprovechando la "descripción pintoresca y romántica del comportamiento de los animales [...] y utilizó como acercamiento a la Historia Natural algunas descripciones que situaban a los lectorcitos en el campo o los alrededores urbanos en los que se podía observar la naturaleza" a través de ejemplos de especies con los cuales se instruía, entretenía y moralizaba al público. ${ }^{20}$

Una de las obras científicas de las que se extrajeron varias monografías zoológicas para la prensa divulgativa fue la Historia Natural (1749-1767) del

16 Adelina Arredondo, "La formación de los ciudadanos de la primera República Federal mexicana a través de un texto escolar (1824-1834)", en Lecturas y lectores en la historia de México, coord. Carmen Castañeda, Luz Elena Galván y Lucía Martínez (México: CIESAS, El Colegio de Michoacán, Universidad Autónoma del Estado de Morelos, 2004), 75.

17 Emilio Palacios, "Las fábulas de Félix María de Samaniego: fabulario, bestiario, fisiognomía y lección moral", Revista de Literatura Vol.: 60 No. 119 (1998): 90.

18 Véase Joseph Lancaster, Improvements in Education, as it respects the Industrious Classes of the Community, containing, a short account of its present state, hints towards its improvement, and a retail of some practical experiments conduvive to that end (Londres: Darton and Harvey, 1803).

19 Sylvie Imparato-Prieur, "Las Fábulas literarias de Iriarte: ¿un clásico reactualizado de la literatura infantil?”, en Ilustración, ilustraciones, Tomo II, eds. Jesús Astirraga, María Victoria López-Cordón y José María Urkia (San Sebastián: Real Sociedad Bascogada de los Amigos del País, Ministerio de Cultura, 2009), 813.

20 Jean-Marc Drouin y Bernadette Bensaude-Vincent, "Nature for the people", en Cultures of natural history, ed. Nick Jardine, James Secord y Emma Spary (Cambridge: Cambridge University Press, 1996), 410. 
célebre Georges Louis Leclerc, conde de Buffon (1707-1788). En Francia se llevaron a cabo "innumerables breviarios, recopilaciones, diálogos o textos escogidos [...] diseñados para una lectura privada en familia o pública en el aula", por ejemplo, Le Buffon des écoles (1802) y Le Buffon des enfants (1811) que rápidamente se tradujeron a otras lenguas. ${ }^{21}$ Es evidente que el redactor del Diario de los Niños echó mano de tales libros infantiles para nutrir a la revista mexicana.

A la par de los libros, las revistas infantiles ofrecían "una lectura moderna, atractiva, variada y laicizada, tendiente a crear a un lector ávido del conocimiento" científico que no estaba disponible en las aulas hacia 1839-1840. Lo anterior se aprecia en las palabras iniciales del segundo volumen del Diario de los Niños, tituladas "A los niños" (1840). Sánchez de la Barquera expresó a los lectorcitos y padres que unidos recorrerían "una senda cual [era] la de la inteligencia, en la que a pesar de [su corta edad, ya habían] dado los primeros pasos. Juntos [estudiarían] las deliciosas composiciones de la imaginación del hombre, sus curiosos y útiles descubrimientos en las ciencias". ${ }^{22}$ Las palabras del redactor destacaron a las ciencias, rubro que consideraba de interés para los niños, pues su aprendizaje no estaba formalizado por la escuela. Es factible que los padres pertenecientes a las profesionales científicas (médicos, farmacéuticos e ingenieros), a la par que empresarios que explotaban las riquezas naturales (minas, haciendas y bosques), consideraran positiva la oferta de instruir a los hijos en el ámbito de la ciencia a través del Diario de los Niños.

\section{Zoología instructiva}

En el Diario de los Niños la instrucción científica sobre los animales estuvo acorde con la edad y las vivencias del público bajo una retórica amena orientada a despertar su curiosidad por la diversidad faunística. Los contenidos zoológicos emplearon "la descripción de las costumbres y comportamientos de las diferentes especies animales, así como de sus rasgos morfológicos y anatómicos". ${ }^{23}$ Para ello, los autores recurrieron a una hipotética observación

21 Antonio Lafuente y Javier Moscoso, "Ciencia mundana y ciencia popular: estilo y sensibilidad en la historia natural de Buffon", en Las dos orillas de la ciencia. La traza pública e imperial de a Ilustración española, ed. Antonio Lafuente (Madrid: Fundación Jorge Juan, Marcial Pons Historia, 2012), 217.

22 Redactor, "A los niños", Diario de los Niños. Literatura, Entretenimiento e Instrucción Vol.: 2 (1840): 1.

23 Arturo Morgado, "La visión del mundo animal en la España del siglo XVII: el Bestiario de Covarrubias", Cuadernos de Historia Moderna No. 26 (2011): 74. 
de los animales en su hábitat que descubriera a los lectorcitos los hábitos de cada especie (alimentación, reproducción y depredadores), el medio ambiente que habitaban (clima, territorio y flora) y la descripción del cuerpo resaltando las características más llamativas (colores, olores, formas y dimensiones). Con estos tres elementos se consideraba que los niños se instruirían científicamente en el hogar.

Uno de los escritos zoológicos que aportó un panorama de la fauna del mundo se tituló "Geografía zoológica" (1840). En este se explicó a los niños la relación existente entre fauna clima, altitud y vegetación, pues el vínculo entre los elementos permitía el desarrollo de las especies. Por ejemplo, "el camello con sus anchos pies, sus siete estómagos, su sobriedad, su paciente sed, solo [existía] en medio de arenales movibles, de desiertos áridos y secos, de soledades africanas", pues la anatomía y fisiología de cada especie estaba relacionada con la región del mundo que habitaba. ${ }^{24}$ Esto aportó una perspectiva amplia de la distribución zoológica en varias partes del mundo que pudo interesar a los infantes, al relacionar algunas especies que conocían con el entorno geográfico. Es de suponer que algunos de ellos se habrían preguntado por las especies mexicanas que conocían y las regiones que habitaban.

Uno de los artículos zoológicos más representativos en cuanto al tema de la instrucción sobre las especies llevó el título de "El halcón" (1840). Este conjugó la anatomía, hábitos y cualidades de esta ave. El anónimo autor escribió que

Dotado este noble pájaro de una intrepidez poco común, de un ardor sin igual en el combate, si tuviera tanta fuerza como [poseía] valor, disputaría al águila el imperio de los aires [...] Las partes que [servian] para ejercer y rapaz, [eran] pico, alas, garras y [merecían] una descripción particular. La mandibula superior [era] encorvada y [tenía] de cada lado dos especies de dientes agudos, la mandibula inferior, ligeramente convexa, también [era] puntiaguda. Este pico agudo y filoso [hacía] crueles heridas. ${ }^{25}$

Es evidente que las partes corporales del halcón se basaron en un lenguaje sencillo desprovisto del academicismo naturalista. Es probable que la detallada descripción del pico atrajera la atención de los lectorcitos debido a los

24 Anónimo, “Geografía zoológica”, Diario de los Niños. Literatura, Entretenimiento e Instrucción Vol.: 3 (1840): 174.

25 Anónimo, "El halcón”, Diario de los Niños. Literatura, Entretenimiento e Instrucción Vol.: 3 (1840): 287. 
hábitos de caza del ave que se apreciaban en los alrededores de la capital. Es de suponer que en las familias de clase alta se practicara la cetrería, así como la taxidermia de animales para formar colecciones zoológicas privadas. Este tipo de exposición científica guarda similitudes con los escritos publicados en la prensa divulgativa para adultos de la época. Las escasas diferencias estribaron en la extensión del escrito y en la inclusión de aspectos fisiológicos considerados propios de la edad adulta.

En tono similar, el escrito "La lira" (1839) describió la anatomía y hábitos de un pájaro australiano que debía su nombre a la semejanza de la cola con dicho instrumento musical. No obstante, el nombre científico era Menura superba. Este había sido otorgado por el zoólogo inglés John Latham (1740-1837) que en 1802 recibió un ejemplar de parte de unos exploradores asentados en Nueva Holanda (actual occidente de Australia). El escrito expuso a los lectorcitos una interesante polémica ornitológica que se llevaba a cabo al final de la década de 1830 acerca de la determinación taxonómica de esta ave. Algunos naturalistas consideraban necesario crear una nueva familia en el Reino Animal denominada Menuridae que alojara a esta especie tan distinta de las ya conocidas, mientras que otros consideraban que pertenecía a familias tradicionales como la Phasianidae por el parecido de la cola en forma de lira con las hermosas colas del pavo real y el faisán, otros zoólogos suponían que la Menura superba pertenecía a la familia Paradisaeidae conformada por las elegantes aves del paraíso, pues Nueva Guinea y Nueva Holanda eran islas cercanas. ${ }^{26}$

Entre las peculiaridades del ave lira estaba el agradable canto y la capacidad de imitar el sonido de otros pájaros de Nueva Holanda. Por esta razón, algunos zoólogos europeos opinaban que era pariente de los bellos cenzontles mexicanos de la familia Mimidae, una de las aves más conocidas en el centro del país. ${ }^{27}$ La sencilla explicación de la polémica zoológica puso en contacto a los lectores con la práctica naturalista llevada a cabo en la esfera académica de Europa y América, a la par que los introdujo en el mundo de las exploraciones científicas que se llevaban a cabo en la época, incluyendo México, y evidenció el papel de los naturalistas, todos ellos varones, como actores fundamentales de la Zoología.

26 Anónimo, "La lira", Diario de los Niños. Literatura, Entretenimiento e Instrucción Vol.: 1 (1839): 73.

27 Anónimo, "La lira", 73. 
El autor explicó a los lectorcitos que en cuanto a la reproducción, la hembra construía en el suelo un nido compuesto de yerbas y hojas secas. Una vez al año esta empollaba entre 12 y 16 huevos blancos con pintas azules. Cuando nacían los polluelos, era difícil cogerlos, "porque aunque [eran] muy pequeños, [corrían] con suma ligereza y [sabían] ocultarse en los matorrales" ${ }^{28}$ A pesar de la sencillez de la exposición de las características reproductivas, es de suponer que el público habría recordado las distintas aves de la ciudad de México en cuanto a la temporada de apareamiento, el nacimiento de los polluelos y el crecimiento de estos, por ejemplo las palomas, ruiseñores y demás aves canoras que anidaban en los árboles de la Alameda, Chapultepec y los jardines privados.

\section{Zoología exótica}

Los contenidos sobre animales exóticos fueron recurrentes en la prensa decimonónica, pues las diferentes expediciones científicas por todo el orbe descubrían nuevas especies. Desde el siglo XVI, el estudio y "posesión de animales extraños y fieras salvajes [era] una de las grandes aficiones de la aristocracia [...] y considerados prestigiosos objetos de lujo y símbolos de distinción" que se exhibían en colecciones disecadas, pequeños zoológicos, láminas de libros e imágenes en tapices, vitrales y esculturas. ${ }^{29}$ La cultura zoológica era parte de los saberes científicos elitistas que los infantes debían conocer para apartarse de otros grupos sociales que no estaban en contacto con la fauna de lejanos países.

La aproximación de algunos niños con la fauna exótica marcaba una distinción frente a sus pares de estratos bajos. La mayoría de los infantes capitalinos estaba en contacto con la fauna local, mientras que solo aquéllos con padres dispuestos a comprar lujos culturales, como las revistas, se adentraban en el conocimiento de animales africanos, asiáticos y europeos. En este rubro, el redactor del Diario de los Niños incluyó algunos extractos de obras de reconocidos científicos, como Buffon. La presencia de una de las autoridades zoológicas del mundo científico fue un distintivo de la revista, ya que los infantes se acercaban al medio académico europeo de la Historia Natural.

28 Ibíd., 75 .

29 Carlos Gómez-Centurión, "Exóticos pero útiles: los camellos reales de Aranjuez durante el siglo XVIII", Cuadernos dieciochistas No. 9 (2008): 161. 
Uno de los artículos de Buffon se tituló “El león” (1840). En este se destacó la belleza anatómica del felino, a la vez que se exaltó "su mirada firme y atrevida, porte altivo y terrible voz" que lo hacían merecedor al epíteto de rey de los animales. Mientras que la leona fue caracterizada por el amor hacia los cachorros que la hacían que fuera "no menos fiera y temible que el macho", siguiendo las pautas del "deber ser" de la hembra. ${ }^{30}$ Tal visión maternal de la leona estuvo encaminada a reforzar las características "naturales" de las hembras en cuanto al cuidado de las crías. Este tipo de ejemplos expuso a los lectorcitos que la diferencia entre padres y madres iba más allá de la sociedad, pues en la naturaleza las diferencias entre unos y otros eran tajantes.

Es de resaltar que casi todos los escritos zoológicos del Diario de los Niños iniciaron con la exposición de la especie a través de un macho adulto, en este caso el león, para después dar paso a la hembra y las crías. Esto se debió a que la Zoología se basaba en el estudio de los individuos y no en las comunidades como sucede en la actualidad. De igual manera, la narración científica del individuo estuvo a tono con la determinación del "ejemplar tipo" que para los cánones taxonómicos de la época siempre se trataba de un macho. Cuando los zoólogos solo hallaban a la hembra se consideraba que el estudio zoológico estaba incompleto. La primacía del macho frente a la hembra en la divulgación faunística reforzaba las distancias de género existentes en la sociedad occidental justificadas a través de la "naturalidad" de estas. Una cuestión que se aprendía desde la infancia a través de la ciencia.

De Buffon también se incluyó "El tigre" (1839), un felino considerado por el naturalista como similar al león, aunque

el tigre [era] vilmente feroz y cruel sin justicia [...] El primero, que todo lo [podía], [era] menos tirano que el otro que no pudiendo disfrutar de la suprema potestad se [vengaba] de ello abusando del poder que [podía] arrogarse [...] El tigre, aunque [estaba] saciado, siempre [parecía] sediento de sangre. Su furor no [conocía] más treguas que el tiempo necesario para armar emboscadas, [agarraba] y [despedazaba] una nueva presa. ${ }^{31}$

La caracterización moral del tigre fue común en las narraciones de la fauna exótica, pues en lugar de resaltar las características anatómicas y de con-

30 Buffon, "El león”, Diario de los Niños. Literatura, Entretenimiento e Instrucción Vol.: 3 (1840): 265.

31 Buffon, "El tigre", Diario de los Niños. Literatura, Entretenimiento e Instrucción Vol.: 1 (1839): 59. 
ducta, como en la instrucción zoológica, los autores daban importancia al comportamiento bajo la mirada humana. Con la traducción libre del escrito de Buffon, Sánchez de la Barquera consideró que los niños aprenderían valores morales para la vida adulta, como la temperancia, la clemencia y el valor, aspectos del león (modelo a seguir) y distantes del tigre (modelo de repulsión social).

El escrito también señaló que al final del siglo XVIII, en el Real Gabinete de Historia Natural de París se hallaba expuesto un tigre disecado de casi 8 pies de longitud que desde joven había sido llevado a la Casa de las Fieras, es decir, al zoológico privado de los monarcas franceses. ${ }^{32}$ Sin embargo, tras la Revolución francesa los acervos naturalistas fueron abiertos a todo el público, pues el conocimiento de la fauna exótica ya no estaba reservado a la élite. Es de suponer que la mención del acervo zoológico francés, como espacio de aprendizaje informal de los animales, alentaría al público infantil a conocer el Gabinete de Historia Natural capitalino que exhibía a los visitantes muestras de la fauna del país.

Uno de los animales más exóticos de mediados del siglo XIX fue el orangután, pues hasta 1799 se le creía parte de la fauna mítica de las islas de la actual Indonesia. En ese año, el naturalista francés Bernard de Lacépède (1756-1825) estudio científicamente al género Pongo. No obstante, hasta 1827 el zoólogo René Primevère Lesson (1794-1849) describió al orangután de Sumatra o Pongo abelii, protagonista de un artículo publicado en 1839 en el Diario de los Niños. Es de presumir que varios infantes habrían querido leer sobre un animal que parecía fantástico y del que se conocían pocos especímenes fuera de Asia.

El artículo relató el viaje de un explorador que recorría la isla de Sumatra cuando encontró en una cueva en medio de la selva a "un animal que tanto se [asemejaba] al hombre". ${ }^{33}$ Los lectorcitos se adentraron a la anatomía de tan extraño animal al leer que su "frente era redonda y prominente, sus ojos expresivos, guardándolos un par de cejas bien dibujadas” y el cuerpo cubierto de un vello anaranjado que le proporcionaba un color único entre los primates. ${ }^{34}$ La anatomía del orangután fue descrita bajo un lenguaje ameno

33 Anónimo, "Historia de un orang-utang", Diario de los Niños. Literatura, Entretenimiento e Instrucción Vol.: 1 (1839): 297.

34 Anónimo, "Historia de un orang-utang", 298. 
que buscaba instruir a la vez que entretener para despertar la imaginación sobre animales de regiones lejanas.

Los viajes de exploración en las revistas infantiles fueron una estrategia recurrente para adentrar a los lectorcitos en la práctica científica al subrayar el valor, penurias y esfuerzo que requería la práctica naturalista. Sin embargo, los hombres de ciencia que perseveraban en las empresas científicas eran recompensados con la emoción de descubrir nuevas especies que les otorgaban un lugar en los círculos académicos. Tal vez este tipo de narraciones despertaran la vocación de algunos niños por las profesiones científicas y el reconocimiento del territorio mexicano que aún albergaba animales desconocidos.

Otro escrito de Buffon fue sobre el rinoceronte, uno de los animales más conocidos desde la antigüedad a través de relatos e ilustraciones, pero que pocos individuos habían tenido el placer de contemplar en su medio natural o en una colección científica. Una de sus peculiaridades era el cuerno ubicado más arriba de la nariz que se empleaba como arma contra los depredadores. En las sociedades "salvajes" este era tan valorado como el marfil, no tanto por la elaboración de objetos suntuarios, sino en términos farmacéuticos, pues en Asia los polvos provenientes del cuerno se consideraban útiles para aliviar varias dolencias. Además, la piel, sangre, orina y excrementos eran estimados como antídotos contra el veneno o como remedios para muchas enfermedades tropicales. ${ }^{35}$ La mención a la terapéutica popular de los pueblos "bárbaros" fue un tópico común al abordar la fauna exótica y en varias ocasiones los autores exponían sus prejuicios acerca de las prácticas que no estaban sancionadas por la Farmacia. Así se transmitía un mensaje a los niños sobre las bondades de la ciencia (racional) frente al conocimiento popular (supersticioso), como el caso de las sociedades indígenas.

\section{Zoología curiosa}

Las peculiaridades de los seres vivos constituyó un tema distinto a los dos anteriores. Este tipo de escritos fueron reducidos en extensión, carecieron de elementos anatómicos o del comportamiento de las especies, aunque enfatizaron aspectos extraordinarios de estas y, en ocasiones, centraron la aten-

35 Buffon, "El rinoceronte", Diario de los Niños. Literatura, Entretenimiento e Instrucción Vol.: 2 (1840): 464. 
ción del lectorcito en la explotación de los recursos animales (terapéutica, agricultura y comercio). Ejemplo de ello fue la "Prodigiosa fecundidad de los peces" (1839) que expuso a los niños la enorme población de especies marinas conformada por "animalitos microscópicos, innumerables gusanitos", millones de peces y moluscos, cientos de mamíferos, además de seres aún desconocidos por los naturalistas. ${ }^{36}$

La dilatada reproducción de los animales marinos fue ejemplificada con el estudio del célebre Anton van Leeuwenhoeck (1632-1723) que calculó que el arenque (Clupea spp.) en promedio desovaba 10000 huevos a lo largo de la vida y la carpa (Cyprinus carpio) producía 262224 huevos en el mismo lapso. Con estas cifras se esperaba que los infantes percibieran "la inagotable fecundidad de la naturaleza". ${ }^{37}$ Tal ejercicio requería de nociones de aritmética adquiridas en la escuela y de cierta reflexión sobre la vida de los peces, por ejemplo, aquéllos que se consumían en la vida diaria, en especial, en la cuaresma de cada año.

El aprovechamiento de los mamíferos de gran tamaño como fuerza productiva era común en el siglo XIX, aunque el escrito sobre los "Ratones operarios" (1839) debió atraer a los infantes, ya que los roedores eran considerados como fauna nociva al transmitir varias enfermedades. No obstante, el anónimo autor señaló que en Kirkaldy, Escocia, sir Alton Dusferlin, un empresario local, estaba dando los primeros pasos para convertir a estos en animales productivos para el hombre. En dicha ciudad se estableció la primera colonia manufacturera de tinte ratonil que producía 2300 libras esterlinas anuales al propietario. Los ratones se habían convertido en animales que "trabajaban, [ganaban] su subsistencia, [aumentaban] la riqueza del hombre y [eran] jornaleros" ${ }^{38}$ Este comentario resaltó el ingenio de un hombre instruido en la Zoología para transformar a los ratones de molestos mamíferos en seres productivos en términos económicos. Este tipo de escritos estuvieron encaminados a explicar a los menores de edad que las disciplinas científicas tenían una vertiente útil a la sociedad, tan solo se requería de instrucción en los cánones de la Historia Natural.

\footnotetext{
36 Anónimo, "Prodigiosa fecundidad de los peces", Diario de los Niños. Literatura, Entretenimiento e Instrucción Vol.: 1 (1839): 453.

37 Anónimo, "Prodigiosa fecundidad de los peces", 453.

38 Anónimo, "Ratones operarios", Diario de los Niños. Literatura, Entretenimiento e Instrucción Vol.: 1 (1839): 447.
} 
Entre los fenómenos naturales en que la fauna estaba involucrada resaltó la "lluvia animal" que despertaba la curiosidad en varias partes del mundo y el Diario de los Niños no fue la excepción. El redactor consideró importante explicar un acontecimiento sorprendente que tuvo lugar en febrero de 1836 en Lombardía, Italia. Durante una nevada en los Alpes, los habitantes de la zona observaron que la blancura de la nieve se tornaba oscura. "Sorprendidos sobremanera por tan extraordinario suceso se acercaron a ver y examinar la causa y observaron un enjambre prodigioso de gusanos de color oscuro que caían de las nubes con abundancia" hasta teñir la nieve de color chocolate. ${ }^{39}$

Algunos naturalistas italianos se propusieron informar al país de que tal fenómeno no se debía a fuerzas sobrenaturales, sino que las tormentas marinas al estar en contacto con pantanos arrastraban larvas, insectos y moluscos "que [eran] atraídos y arrebatados por la furia de los vientos a puntos distantes" en forma de lluvia. ${ }^{40}$ La explicación sobre un fenómeno que parecía violar las leyes naturales intentó aportar a los niños mexicanos una base científica y racional para comprender tal situación y evitar que estos recurrieran a elementos supersticiosos del 'populacho'.

\section{CONCLUSIÓN}

La historia social de la ciencia echa mano de la prensa como una fuente indispensable para comprender cómo el conocimiento científico circuló para estar al alcance de las clases media y alta urbanas, ya fuera mediante la instrucción o el entretenimiento. Así mismo, la prensa fungió como vía para fortalecer las relaciones de las ciencias con diversos públicos, pues se esbozó como una autoridad discursiva para convencer a los lectores de la importancia de apoyar, por todos los medios posibles, la investigación de la naturaleza.

La hemerografía infantil permite conocer las vías en que se diseminó la instrucción informal de las ciencias en la ciudad de México a mediados del siglo XIX y da pie a cuestionar la historiografía tradicional que señala a la escuela de primeras letras como el ámbito hegemónico de la instrucción. Los saberes científicos eran aprendidos por niños y niñas en el hogar mediante libros,

39 Anónimo, "Lluvia animal", Diario de los Niños. Literatura, Entretenimiento e Instrucción Vol.: 1 (1839): 207.

40 Anónimo, "Lluvia animal", 208. 
revistas, preceptores particulares y padres de familia. La popularización de la ciencia estuvo basada en la simpleza del lenguaje, la amenidad narrativa y el precio asequible de los fascículos. Esto propició que algunos infantes de clases media y alta de la capital se adentraran en la práctica científica sin el rigor del aula.

La Zoología instructiva aportó elementos científicos a los infantes para descubrir la diversidad de la fauna del mundo desde parámetros anatómicos, reproductivos y del hábitat. No se esperaba que los lectorcitos memorizaran los contenidos científicos como sucedía en el aula, sino que se entretuvieran a través de la instrucción y relacionaran lo aprendido con su vida diaria. Mientras que el exotismo zoológico debió despertar la imaginación de los niños al entrar en contacto con animales desconocidos en México. De la mano de autoridades científicas, los menores de edad incursionaban en territorios lejanos que los naturalistas escudriñaban in situ para luego transportar los animales a las instituciones científicas. Es probable que la curiosidad zoológica interesara a los jovencitos y despertara su imaginación sobre fenómenos extraños de la naturaleza o hábitos inusitados de algunas especies, entre otros temas. Los tres tópicos fueron recurrentes en numerosas revistas mexicanas de la época.

La ciencia europea en el Diario de los Niños fue un referente constante en el ámbito zoológico, en especial Inglaterra y Francia, a tono con el resto de publicaciones capitalinas y las cátedras de las escuelas científicas mexicanas de la época. En este sentido, la presencia de los naturalistas y establecimientos del Viejo Continente dirigió la mirada de los lectorcitos hacia la cultura europea como un modelo a seguir.

Es de presumir que fue tal el éxito del Diario de los Niños que el impresor García Torres se aventuró a publicar dos libros para niños de Manuel Benito Aguirre: Los niños pintados por ellos mismos (1843) y Las niñas pintadas por ellas mismas (1846). En menos de una década se conformó un pequeño grupo de lecturas infantiles de carácter mexicano a partir de una revista en tres volúmenes y dos libros que instruyeron y entretuvieron a varios niños de la ciudad de México. Tal vez algunos de los estudiantes del Colegio de Minería y de la Escuela de Medicina se interesaron desde sus tiernos años en incursionar en las profesiones científicas a través de los escritos de ciencias naturales del Diario de los Niños. 


\section{FUENTES}

Anónimo, "Geografía zoológica", Diario de los Niños. Literatura, Entretenimiento e Instrucción Vol.: 3 (1840): 174-177.

Anónimo, "El halcón", Diario de los Niños. Literatura, Entretenimiento e Instrucción Vol.: 3 (1840): 287-291.

Anónimo, "Historia de un orang-utang", Diario de los Niños. Literatura, Entretenimiento e Instrucción Vol.: 1 (1839): 297-303.

Anónimo, “La lira”, Diario de los Niños. Literatura, Entretenimiento e Instrucción Vol.: 1 (1839): 73-76.

Anónimo, "Lluvia animal”, Diario de los Niños. Literatura, Entretenimiento e Instrucción Vol.: 1 (1839): 207-209.

Anónimo, "Prodigiosa fecundidad de los peces", Diario de los Niños. Literatura, Entretenimiento e Instrucción Vol.: 1 (1839): 453-454.

Anónimo, "Ratones operarios", Diario de los Niños. Literatura, Entretenimiento e Instrucción Vol.: 1 (1839): 447-448.

Buffon, "El león", Diario de los Niños. Literatura, Entretenimiento e Instrucción Vol.: 3 (1840): 265-272.

Buffon, "El rinoceronte", Diario de los Niños. Literatura, Entretenimiento e Instrucción Vol.: 2 (1840): 457-471.

Buffon, "El tigre", Diario de los Niños. Literatura, Entretenimiento e Instrucción Vol.: 1 (1839): 58-62.

Redactor, "A los niños", Diario de los Niños. Literatura, Entretenimiento e Instrucción Vol.: 2 (1840): 1.

\section{REFERENCIAS}

Arredondo, Adelina. "La formación de los ciudadanos de la primera República Federal mexicana a través de un texto escolar (1824-1834)". En Lecturas y lectores en la historia de México, coordinado por Carmen Castañeda, Luz Elena Galván y Lucía Martínez. México: CIESAS, El Colegio de Michoacán, Universidad Autónoma del Estado de Morelos, 2004, 67-87.

Burke, Peter. Historia social del conocimiento. De Gutemberg a Diderot. Barcelona: Paidós, 2002.

Caspard, Pierre. "La infancia, la adolescencia, la juventud: para una economía política de las edades desde la época moderna". En La infancia y la cultura escrita, coordinado por Lucía Martínez. México: Siglo XXI/Universidad Autónoma del Estado de Morelos, 2001, 77-101.

Castro, Miguel Ángel y Guadalupe Curiel. Publicaciones periódicas mexicanas del siglo XIX: 1822-1855. México: Universidad Nacional Autónoma de México, 2000.

Sánchez Cerezo, Sergio, Diccionario de las ciencias de la educación. México: Santillana, 1997. 
Drouin, Jean-Marc y Bernadette Bensaude-Vincent. "Nature for the people". En Cultures of natural history, editado por Nick Jardine y James Secord. Cambridge: Cambridge University Press, 1996, 408-425.

Gómez-Centurión, Carlos. “Exóticos pero útiles: los camellos reales de Aranjuez durante el siglo XVIII". Cuadernos dieciochistas No. 9 (2008): 155-180.

Imparato-Prieur, Sylvie. "Las Fábulas literarias de Iriarte: ¿un clásico reactualizado de la literatura infantil?". En Ilustración, ilustraciones, tomo II, editado por Jesús Astirraga, María Victoria López-Cordón y José María Urkia. San Sebastián: Real Sociedad Bascogada de los Amigos del País, Ministerio de Cultura, 2009, 811-830.

Lafuente, Antonio y Javier Moscoso. “Ciencia mundana y ciencia popular: estilo y sensibilidad en la historia natural de Buffon". En Las dos orillas de la ciencia. La traza pública e imperial de a Ilustración española, editado por Antonio Lafuente. Madrid: Fundación Jorge Juan/Marcial Pons Historia, 2012, 215-232.

Lancaster, Joseph. Improvements in Education, as it respects the Industrious Classes of the Community, containing, a short account of its present state, hints towards its improvement, and a retail of some practical experiments conduvive to that end. Londres: Darton and Harvey, 1803.

Morgado, Arturo. "La visión del mundo animal en la España del siglo XVII: el Bestiario de Covarrubias". Cuadernos de Historia Moderna No. 36 (2011): 67-88.

Padilla, Antonio. "Rostros en el cristal: infancias y modalidades educativas (a modo de introducción)". En Arquetipos, memorias y narrativas en el espejo: infancia anormal y educación especial en los siglos XIX y XX, coordinado por Antonio Padilla. México: Juan Pablos editor, Universidad Autónoma del Estado de Morelos, 2012, 23-59.

Palacios, Emilio. “Las fábulas de Félix María de Samaniego: fabulario, bestiario, fisiognomía y lección moral”. Revista de Literatura Vol: 60 No. 119 (1998): 79-100.

Rezende, Moema de. "Ensaio sobre o termo 'vulgarização científica' no Brasil do século XIX". Revista Brasileira de História da Ciência Vol.: 1 No 2 (2008): 137-145.

Santiago, Zoila. "Los niños en la historia. Los enfoques historiográficos de la infancia". Takwá No. 11-12 (2007): 31-50.

Saavedra, Manuel. Diccionario de Pedagogía. 500 términos especializados. México: Pax, 2001.

Tanck, Dorothy. La educación ilustrada 1786-1836. Educación primaria en la ciudad de México. México: El Colegio de México, 2005.

Topham, Jonathan. "Scientific Publishing and the Reading of Science in Nineteenthcentury Britain: A Historiographical Survey and Guide to Sources". Studies in History and Philosophy of Science No. 31 (2000): 559-612.

Vega y Ortega, Rodrigo. "La Zoología y el Diario de los Niños (ciudad de México, 1839-1840)". Revista Historia de la Educación Latinoamericana. Vol. 15 No, 20, (2013): 275 - 293. 